\title{
The current state and future perspectives of high intensity focused ultrasound (HIFU) ablation for benign thyroid nodules
}

\author{
Iwona Pałyga ${ }^{1,2}$, Robert Pałyga ${ }^{2}$, Jacek Młynarczyk ${ }^{3}$, Janusz Kopczyński ${ }^{4}$, Stanisław Góźdź ${ }^{2,5}$, \\ Aldona Kowalska ${ }^{1,2}$ \\ ${ }^{1}$ Endocrinology Clinic, Holycross Cancer Center, Kielce, Poland; ${ }^{2}$ The Faculty of Health Sciences, Jan Kochanowski University, Kielce, Poland; \\ ${ }^{3}$ Department of Radiology, ${ }^{4}$ Department of Surgical Pathology, ${ }^{5}$ Oncology Clinic, Holycross Cancer Center, Kielce, Poland \\ Contributions: (I) Conception and design: I Pałyga, A Kowalska; (II) Administrative support: S Góźdź; (III) Provision of study materials or patients: \\ I Pałyga, A Kowalska, R Pałyga, J Młynarczyk, J Kopczyński; (IV) Collection and assembly of data: I Pałyga, A Kowalska; (V) Data analysis and \\ interpretation: I Pałyga, A Kowalska; (VI) Manuscript writing: All authors; (VII) Final approval of manuscript: All authors. \\ Correspondence to: Iwona Pałyga. ul. Artwińskiego 3, 25-734 Kielce, Poland. Email: iwonapa@tlen.pl.
}

\begin{abstract}
High intensity focused ultrasound (HIFU) is a new thermoablation technique used to treat benign thyroid nodules. In this method, the ultrasound beam passes through the patient's skin and focuses very precisely on the target lesion at a distance far from the source of ultrasound generation, making HIFU the only truly non-invasive method of thermoablation developed to date. HIFU is therefore an attractive alternative to surgery and other thermoablative techniques. This review describes the principles of HIFU treatment, the selection of patients suitable for HIFU, the course and effects of treatment, and future perspectives.
\end{abstract}

Keywords: High intensity focused ultrasound ablation (HIFU ablation); thermoablation, thyroid nodule

Submitted Oct 09, 2019. Accepted for publication Oct 29, 2019.

doi: $10.21037 /$ gs.2019.10.16

View this article at: http://dx.doi.org/10.21037/gs.2019.10.16

\section{Introduction}

The incidence of thyroid nodules in the general population has been estimated to be as high as $60 \%$ if screened by ultrasound (1). Most (95\%) lesions are benign in nature, with about $15 \%$ of thyroid nodules increasing in size significantly over time (2). Only a small percentage of these nodules, however, cause local problems (2). Because no medical or pharmacological treatments to date, including levothyroxine, have been shown to reduce the size of these nodules (3), thyroid surgery is the primary treatment. Guidelines of the American Thyroid Association (ATA) recommend that patients with growing or symptomatic benign thyroid nodules be referred for thyroid surgery, especially when these nodules are $>4 \mathrm{~cm}$ in diameter or cause local compression symptoms or cosmetic problems (1). Thyroid surgery, however, is associated with a risk of complications, which, although low, include bleeding, infection, damage to the recurrent laryngeal nerve, and hypoparathyroidism, with the latter two possibly being permanent (4). In addition, patients who undergo total thyroidectomy have permanent hypothyroidism, requiring lifetime treatment with levothyroxine. Traditional open thyroidectomy also leaves a visible scar at the base of the neck, a cosmetic problem for many patients. In addition, some patients with medical contraindications to general anesthesia do not qualify for surgery.

The benign nature of most of thyroid lesions and the potential risk of postoperative complications have increased interest in minimally invasive treatments for thyroid nodules. Minimally invasive techniques include percutaneous ethanol injection therapy (PEIT) (5) and thermal ablation methods, such as laser ablation therapy (LAT) (6), radiofrequency ablation (RFA) (7), microwave ablation (MWA) (8), and the latest thermal ablation method, HIFU. PEIT is reserved mainly for treatment of symptomatic cystic nodules, and LAT, RFA and MWA for ablation of solid nodules. These techniques require direct 


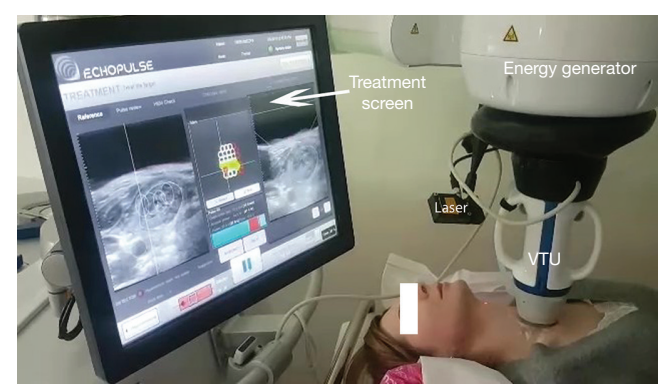

Figure 1 Echotherapy of thyroid nodules-principles of action.

application of energy to areas of treatment by insertion of a needle or probe into the nodule (9).

HIFU is the only truly non-invasive thermoablation method, with no injury to the skin during treatment. During this method, an ultrasound beam generated by the device passes through the patient's skin and focuses very precisely on the target lesion at a distance far from the source of ultrasound generation.

\section{History}

The physical and biological effects of high intensity, high frequency ultrasound waves were first described in 1927 (10). In the 1950s, focused ultrasound energy was used to treat neurological diseases, including Parkinson's disease (11). In connection with the development of technology enabling the parallel use of ultrasound and magnetic resonance imaging (MRI) for real-time navigation and imaging, HIFU has been used since the 1990s to treat several types of solid tumor, including pancreatic (12), prostate (13), renal (14), liver (15) and breast (16), as well as uterine fibroids (17). More recently, HIFU has been used to treat varicose veins and vascular malformations, including in fetuses (18). Also, beginning in $2011 \mathrm{HIFU}$ has been utilized in non-invasive, high-precision treatment of benign thyroid nodules (19).

\section{Physical and biological tissue effects of ultrasound treatment, particularly HIFU}

The biological effects of HIFU have been reviewed (20). The primary effect of ultrasound is a thermal effect, in that tissue absorption of ultrasound causes frictional heating on a microscopic-scale. This heating is generated by shearing caused by variations in longitudinal compression and rarefaction pressure of the ultrasound beam (21). HIFU also has mechanical effects, in that rarefaction of the ultrasound waves can draw gas out of the surrounding tissue, forming microbubbles. These bubbles oscillate with the ultrasound waves and grow in resonance with these waves until violently imploding (22). The simultaneous effects of these two mechanisms are much greater than either acting alone. HIFU also has acoustic streaming effects in that ultrasound waves passing through a fluid can transfer momentum to that fluid (23). This can cause a velocity gradient, which in turn causes shear stress. These physical effects of ultrasound can translate to specific biological effects, which can be used in specific clinical situations. For example, ultrasound treatment for some oncologic indications can cause coagulative necrosis in the tumors [12-15] at temperatures higher than $56^{\circ} \mathrm{C}$, as well as acting as a radiosensitizer or chemosensitizer or assisting drug delivery. Moreover, ultrasound waves can be used to treat thromboses and arteriovenous malformations in patients with rare clinical indications (20).

\section{HIFU therapy of thyroid nodules-principles of action (Figure 1)}

The ECHOPULSE (THERACLION France), is the only commercially device currently available for the treatment (ablation) of thyroid nodules. This device consists of an energy generator, a visualization and treatment unit (VTU), a cooling device, and a touch screen for treatment planning. In HIFU, the piezoelectric transducer generates ultrasonic beams directed toward a three-dimensional focal point. When treating thyroid nodules with a single application, the ultrasound is focused on a cylindrical area measuring $5 \mathrm{~mm}$ in diameter and 7.5 in height. HIFU therapy is based on the joining of two systems, one that generates a highly concentrated ultrasound beam for therapy and the other that allows ultrasound imaging and monitoring of treatment in real time. Two transducers incorporate at the VTU: a HIFU transducer $60 \mathrm{~mm}$ in diameter and with a frequency of $3 \mathrm{MHz}$, which acts as a treatment device and a visualization transducer, composed of 128 crystals and with a frequency of $7.5 \mathrm{MHz}$, which provides both anatomical information and real-time treatment feedback. Ultrasound beams are focused at a depth $5-26.7 \mathrm{~mm}$ below the skin (Figure 2), enabling only nodules or parts of nodules located at this depth to be treated. Because ultrasound treatment of target lesions significant increases temperature $\left(85^{\circ} \mathrm{C}\right)$, a cooling device that prevents burning of the skin is crucial. The cooling device of the ECHOPULSE consists of a balloon located at the end of the VTU filled with a coolant 


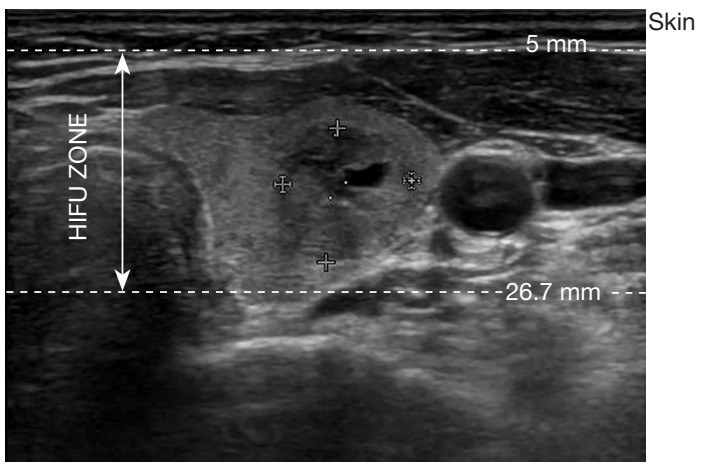

Figure 2 HIFU treatment zone. HIFU, high intensity focused ultrasound.

maintained at $10{ }^{\circ} \mathrm{C}$. The balloon also ensures that the VTU is in close contact with the patient's skin, enabling the ultrasonic wave to reach its target precisely. Finally, the touch screen is used for treatment planning and enables real-time supervision of therapy.

\section{Course of HIFU therapy}

In most centers, HIFU procedures are performed on an outpatient basis. Patients are administered painkillers and sedatives before treatment and are discharged 1-2 hours after treatment. In some centers, patients undergo general anesthesia, which may prolong hospital stay.

HIFU therapy consists of four stages: patient preparation, positioning of the nodule for therapy, treatment planning, and therapy. During all stages, it is essential for patients to lie still on their backs with their heads tilted back. Thus, patients should not undergo HIFU if they have conditions that prevent them from bending their heads back (such as ankylosing spondylitis or osteoarthritis of the cervical spine) and maintaining this non-physiological position for a relatively long period of time. Patient comfort is improved by immobilizing the upper half of the body with a cushion that adapts to body shape. Immobilizing the patient during therapy also limits the possibility of displacement of the target lesion, minimizing the risk of incorrect application of the ultrasound pulse and reducing the risk of possible complications. Safety during treatment is also provided by a laser, which, upon sensing patient movement, immediately interrupts the application of the ultrasound pulse.

The second stage of HIFU is positioning, or identification of the nodule for ablation. The ultrasound control, located in the VTU, is used to set the VTU over the nodule, both manually and with the help of an internal motor. Simultaneously, the planned beam penetration depth is determined. The only VTU position permitted during treatment is perpendicular to the surface of the nodule, as a deviation of the VTU from this axis can damage sensitive structures in the neck. The inability to deflect the VTU makes it impossible to treat some areas with HIFU, including the retrosternal part of the nodule.

The next stage consists of the tedious process of planning therapy. Under real-time ultrasound control, located in the VTU, the physician uses the touch screen to contour the nodule in the sagittal and several transverse planes, allowing the computer to three-dimensionally reconstruct the nodule or region of interest, as well as to automatically suggest the number of applications. At the same time, the physician outlines sensitive structures (e.g., skin, carotid artery, and trachea) on each layer and the software automatically modifies the scope of treatment to protect these sensitive structures. Therefore, the final number of HIFU pulses depends on the size of the nodule and its location relative to sensitive structures.

The fourth stage is therapy, consisting of repeated HIFU pulses lasting for 8 seconds and breaks between pulses for cooling lasting about $40-50$ seconds. The first HIFU application lasts for only 4 seconds and is administered at the automatically determined center of the nodule. This enables initial assessment of the effects of treatment, including the appearance of white hyperechoic marks (HEM) in the treated area (Figure 3). If no HEM is observed on the screen the physician can increase the strength of the applied dose. The duration of the entire procedure for a nodule $3 \mathrm{~cm}$ in diameter is approximately 45 minutes. If the nodule is bigger, or the treatment session consists of two or more layers, the treatment can last for 60-80 minutes.

\section{Patient inclusion criteria}

Only patients with symptomatic thyroid nodules should receive HIFU therapy. Symptomatic nodules include not only nodules that cause local problems (e.g., pressure and choking) or cosmetic defects, but those that significantly increase in size during the observation period. Moreover, HIFU is applicable only to benign nodules, requiring the possibility of malignancy to be excluded before treatment. At least one fine needle aspiration biopsy (FNAB) with benign results has been recommended, as has measuring serum calcitonin concentration to exclude medullary 

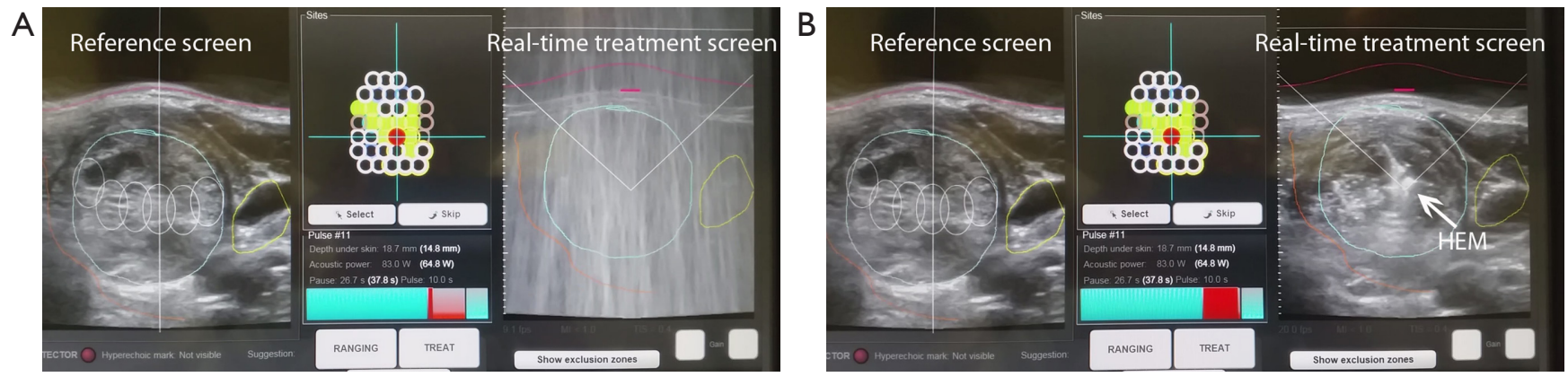

Figure 3 Course of therapy. (A) Propagation of the ultrasound beam; (B) effect of treatment, as shown by the HEM on the screen. HEM, hyperechoic mark.

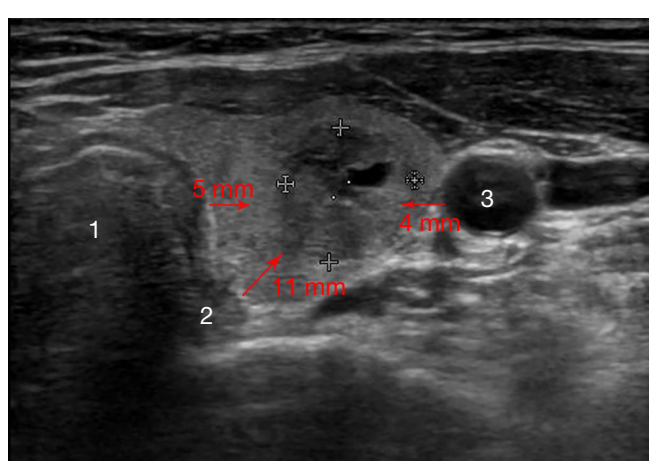

Figure 4 Safety margins from sensitive structures (1, trachea; 2, tracheoesophageal groove; 3 , carotid artery).

thyroid cancer. HIFU is used to treat predominantly solid nodules; if nodules are partially cystic, the cystic part must be evacuated by FNAB prior to HIFU. HIFU treatment is not indicated for patients with simple cystic nodules (because ultrasound beams are dispersed in the liquid part of these nodules) nor for nodules with macrocalcifications (because calcifications reflect ultrasound waves and the acoustic shadow below the areas of calcification prevent the determination of nodule boundaries).

\section{Contraindications to therapy with HIFU}

Patient-related contraindications:

(I) Inability to maintain a stable position with a hyperextended neck;

(II) Tattoo, skin moles, scars on the path the of ultrasound beam passing;

(III) Pre-existing vocal cord palsy;

(IV) History of neck irradiation;

(V) In most studies: age $\leq 18$ years and pregnant or lactating women.

Nodule-related contraindications:

(I) Malignant;

(II) Suspicion of malignancy;

(III) Mostly cystic;

(IV) Large calcifications (macrocalcifications);

(IV) Located close to heat-sensitive structures, including the trachea, esophagus, carotid artery;

(V) Located retroclavically or retrosternally;

(VII) Asymptomatic.

Because sensitive structures must be avoided when administering HIFU to thyroid nodules, safety margins are required. The recommended distances between the focus of the beam and critical structures include (Figure 4):

* Carotid artery-minimum $4 \mathrm{~mm}$;

* Trachea-minimum 5 mm (minimum $10 \mathrm{~mm}$ when in the HIFU post-focal path);

* Tracheoesophageal groove-minimum $11 \mathrm{~mm}$.

Safety margins to protect "sensitive structures" can be provided by delineating part of the thyroid tissue or nodule adjacent to these "sensitive structures", thereby allowing partial treatment of the nodule. This is regarded as acceptable.

\section{Pain control}

During HIFU treatment most patients feel pain caused by propagation of ultrasound waves in tissues located prefocally. The pain lasts for around 8 seconds (the length of an individual treatment pulse), but is relieved during the cooling phase. Some patients experience pain sensations in the thyroid nodule alone, whereas others experience pain in the arms or the back of the neck during treatment pulses. Although the exact explanation of these sensations is unclear, they are believed to result from the propagation 
of ultrasound waves to the area of the paraspinal muscles (24). Pain control during HIFU treatment is crucial. The analgesic and anxiolytic treatment regimens used to date are different at different centers: administered orally (e.g., metamizol and diazepam) or intravenously (e.g., pethidine and diazepam).

A recent study tested the addition of perithyroidal lignocaine (1\%) infusion (PLI) to standard doses of diazepam and pethidine in a group of Chinese patients. Treatment pain was significantly lower in the 104 patients treated with PLI plus diazepam and pethidine than in the 100 patients treated with diazepam and pethidine alone (OR =2.096; 95\% CI, 1.121-3.922, P=0.020). Moreover, older age and lower body mass index were significantly associated with less treatment pain (25).

A study in which 26 nodules with a mean with estimated volume of $2.81 \pm 2.04 \mathrm{~mL}$ indicated that reducing the power of each treatment pulse to its minimum $(33.3 \pm 10.3 \mathrm{~W} /$ site) may allow effective HIFU treatment without any anesthesia or analgesia (26). The mean percent reduction in nodule volume after 12 months was $48 \%$ and 19 (73\%) of the 26 patients experienced comfort without analgesics during treatment, indicating that despite pulse energy being reduced, the treatment was effective. It is worth noting, however, that this study assessed relatively small nodules treated for a relatively short duration (3-18 $\mathrm{min})$.

In conclusion suboptimal analgesic treatment can lead to patient discontinuation of treatment or suboptimal ablation due to reduction of the power of the treatment pulses.

\section{Efficacy of HIFU treatment: (Figure 5)}

In the first feasibility study (19), 25 patients with thyroid nodules underwent HIFU therapy, with three discontinuing treatment due to pain. Two weeks after HIFU therapy, the patients underwent scheduled thyroid surgery for multinodular goiter. Ultrasound images of the nodules were evaluated after HIFU therapy to assess changes in nodule tissue, the resected nodules were analyzed histopathologically to assess the extent of nodule destruction, the main efficacy endpoint, and HIFUinduced damage to surrounding tissues. Of the 22 patients examined, $16(73 \%)$ showed significant ultrasoundinduced changes, with both macroscopic and histological examinations showing that all changes were confined to the targeted nodule without affecting neighboring structures. The extent of nodule destruction ranged from $2 \%$ to $80 \%$, with $5(23 \%)$ patients having pathological changes $>20 \%$ caused. Seventeen patients (77\%) showed nonspecific necrosis, hemorrhage, nodule detachment, cavitations, and cysts, with 12 of these 17 patients showing both ultrasoundinduced changes and cavitation suggestive of the effects of HIFU. Three patients who were ablated at the highest energy level showed significant ultrasound changes and complete coagulative necrosis in $80 \%, 78 \%$, and $58 \%$ of the targeted area. Although the mean volume of treated nodules was small $(0.6 \mathrm{~mL}$; range, $0.05-2.6 \mathrm{~mL})$ compared with the mean total number of ultrasound doses (65; range, 35-145) delivered to the nodule, this study showed that HIFU was effective for ablation of human thyroid nodules, with good safety and tolerability and no major complications.

Currently, the effectiveness of HIFU therapy is assessed primarily by measuring the decrease in volume of the nodule (Table 1). Efficacy has also been evaluated as a change in the echogenicity of the nodule, decreased blood flow by color Doppler, or decreased isotope uptake (technetium- ${ }^{99 \mathrm{~m}} \mathrm{Tc}$ or ${ }^{99 \mathrm{~m}}$ Tc-MIBI-metoxyizobutyloizonitryl) by scintigraphy. Most studies to date have evaluated the effects of HIFU treatment after 3, 6, and 12 months, with few assessing long-term ( $\geq 24$ months) effects. Several relevant studies are presented below.

One study assessed ten nodules in ten patients, with nine finally analyzed (27). All treated nodules were benign, with three being hot or indifferent, and six being cold. Four nodules were solid and five echo complex, with a median pre-intervention volume of $3.5 \mathrm{~mL}$ (range, $0.8-7.7 \mathrm{~mL}$ ). Nodule volume was measured at baseline and at 3 months, and both absolute and relative reduction were measured, as was reduction in scintigraphic uptake in the region of interest using ${ }^{99 \mathrm{~m}} \mathrm{Tc}$-pertechnetate for hot and indifferent nodules and ${ }^{99 \mathrm{~m}} \mathrm{Tc}-\mathrm{MIBI}$ for cold nodules. All nine thyroid nodules decreased in size relative to baseline 3 months after HIFU therapy, with absolute decreases ranging from $0.4-4.7 \mathrm{~mL}$ (median $0.7 \mathrm{~mL}, \mathrm{P}=0.01$ ) and relative decreases ranging from $11.4 \%$ to $75 \%$ (median $48.8 \%$ ). Scintigraphic nodular uptake was also reduced significantly $(\tau=0.66$, $\mathrm{P}=0.02)$, a reduction that correlated with relative reduction in nodular volume ( $\tau=0.44, \mathrm{P}=0.12)$.

Another study, which included 12 patients with a median nodular outline volume of $3.4 \mathrm{~mL}$ (range, $0.6-5.0 \mathrm{~mL}$ ), assessed the effects of HIFU on nodule volume reduction and thyroid function, including serum concentrations of triiodothyronine (T3), thyroxine (T4), thyrotropin (TSH), thyroglobulin (hTg) and antibodies against thyroglobulin (TAbs), thyrotropin receptors (TRAbs) and thyroid peroxidase (TPOAbs) (28). Only serum thyroglobulin 


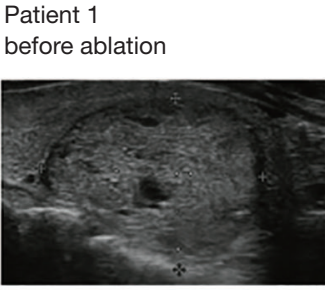

Dimensions: $23 \times 29 \mathrm{~mm}$
6 months

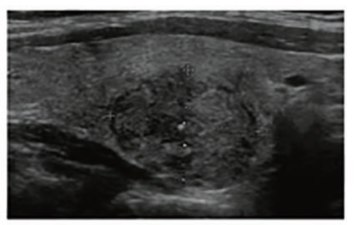

Dimensions: $17 \times 20 \mathrm{~mm}$
Patient 2

before ablation

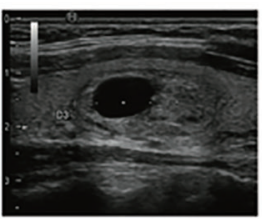

Dimensions: $16 \times 29 \mathrm{~mm}$
6 months

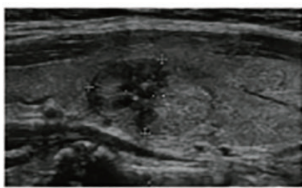

Dimensions: $10 \times 19 \mathrm{~mm}$

Figure 5 US images obtained before and at 6 months after treatment. At 6 months, the volume reduction of the nodule in patient 1 was $65 \%$ in patient $2-68 \%$.

Table 1 Efficacy of HIFU treatment, as assessed by reduction in nodule volume

\begin{tabular}{|c|c|c|c|c|}
\hline $\begin{array}{l}\text { First author and year of } \\
\text { publication }\end{array}$ & $\begin{array}{l}\text { Number of treated } \\
\text { nodules }\end{array}$ & $\begin{array}{c}\text { Nodule volume }(\mathrm{mL}) \text { before } \\
\text { treatment }\end{array}$ & $\begin{array}{c}\text { Volume reduction (\%) after } \\
\text { treatment }\end{array}$ & Last evaluation (months) \\
\hline Esnault 2011 (19) & 22 & $0.6(0.05-2.6)$ & NA & $\begin{array}{l}0.5 \text { (before scheduled } \\
\text { thyroidectomy) }\end{array}$ \\
\hline Korkusuz 2015 (27) & 9 & $3.5(0.8-7.7)$ & $48.8(11.4-75)$ & 3 \\
\hline Korkusuz 2015 (28) & 12 & $3.4(0.6-5.0)$ & 55 & 3 \\
\hline Lang 2017 (30) & 22 & $6.98 \pm 4.04$ & $68.87 \pm 15.27$ & 12 \\
\hline Lang 2017 (31) & 73 & $>30 ; 10-30 ;<10$ & $48.1 ; 67.9 ; 77.6$ & 6 \\
\hline Trimboli 2019 (32) & 26 & $2.81 \pm 2.04$ & 48 & 24 \\
\hline Lang 2019 (33) & 108 & $13.09 \pm 10.54$ & 70.1 & 24 \\
\hline
\end{tabular}

levels were significantly higher 24 hours after than before ablation $(\mathrm{P}<0.05)$, indicating damage to thyroid tissue; these decreased significantly to pre-ablative levels at 3 -month follow-up $(\mathrm{P}<0.05)$. All other hormone and antibody levels were within normal ranges and remained stable $(\mathrm{P}>0.05)$. The median reduction in nodular outline volume was $55 \%$ $(\mathrm{P}<0.05)$.

Treatment with HIFU was also analyzed in 20 euthyroid patients with thyroid nodules (29). Before treatment, mean nodule volume was $4.96 \pm 2.79 \mathrm{~mL}$. At 3 months, mean nodule volume in these 20 patients was $3.05 \pm 1.96 \mathrm{~mL}(\mathrm{P}<0.001)$, decreasing at 6 months to $2.91 \pm 2.43 \mathrm{~mL}(\mathrm{P}<0.001)$ in the 16 patients remaining in the study. At 6 months, the mean volume reduction was $48.7 \% \pm 24.3 \%(\mathrm{P}<0.001)$.

Another study analyzed the effect of HIFU on 22 patients with symptomatic benign thyroid nodules. The primary outcome was the percent change in nodule volume from baseline after 12 months, and ablation success was defined as a $>50 \%$ reduction in nodule volume $(30)$. The mean volume reduction 12 months after HIFU was significant $[68.87 \% \pm 15.27 \%$ (range, 47.35-94.89\%), $\mathrm{P}<0.001]$. Swelling $(\mathrm{P}<0.001)$ and pressure symptom scores $(\mathrm{P}<0.001)$ were also reduced significantly after 12 months, whereas physical composite scores were significantly higher $(\mathrm{P}=0.006)$. These findings indicated that HIFU ablation of symptomatic benign thyroid nodules not only induced significant shrinkage but also improved pressure symptom scores and health-related quality of life (HRQOL) over 12-month. Moreover, a smaller pre-ablation volume nodule was associated with more successful HIFU ablation.

Similarly, another study found that the success of ablation of 73 nodules followed-up for at least 6 months was related to pre-ablation nodule volume (31). Although the overall median 6 -month volume reduction was $68.3 \%$ (range, 22.77-96.50\%), median volume reduction of nodules with pre-ablation volumes of $<10,10-30$, and $>30 \mathrm{~mL}$ were $77.6 \%, 67.9 \%$, and $48.1 \%$, respectively, 
with the reduction in the latter group being significantly lower than those in the other two groups $(\mathrm{P}<0.001)$. These findings indicated that pre-ablation nodule volume $>30 \mathrm{~mL}$ [odds ratio $(\mathrm{OR})=7.813 ; 95 \% \mathrm{CI}, 1.908-32.258 ; \mathrm{P}=0.004)$ and lower total energy per nodule volume ( $\mathrm{OR}=3.313 ; 95 \%$ CI, 1.113-9.688; $\mathrm{P}=0.029)$ were significantly associated with reduced ablation success.

A study of 31 patients with 31 thyroid nodules of major diameter 17-34 mm and median estimated nodule volume of $5.48 \mathrm{~mL}$ analyzed the effects of HIFU treatment after 24 months, with a volume reduction rate (VRR) $>50 \%$ defined as successful (32). Two years after HIFU, overall median nodule volume was $3.40 \mathrm{~mL}$, a significant reduction $(\mathrm{P}<0.0001)$, with a VRR of $43.3 \%$; in addition, $26(83.9 \%)$ lesions were reduced in size. VRR $>50 \%$ was observed after 6,12 , and 24 months in 2 (6.4\%), 5 (16.1\%), and 7 (22.5\%) nodules, respectively.

Another study assessed VRR after 24 months in 108 patients, with a mean nodule volume $13.09 \pm 10.54$, treated with a single HIFU ablation (33). Mean ( \pm SD) VRRs 3, 6, 12,18 and 24 months after treatment were $51.32 \% \pm 20.71 \%$, $62.99 \% \pm 22.05 \%, 68.66 \% \pm 18.48 \%, 69.76 \% \pm 17.88 \%$, and $70.41 \% \pm 17.39 \%$, respectively. Small pre-ablation nodule volume was a significant determinant of treatment success at 24 months ( $\mathrm{OR}=1.045$; 95\% CI, 1.021-1.092, $\mathrm{P}=0.038)$.

\section{Treatment success prediction}

Nodule volume is the most critical parameter predicting the success of HIFU treatment, with smaller nodule volume being associated significantly with greater volume reduction after treatment (27-31). Moreover, shallower nodules are associated with greater relative nodule shrinkage than nodules located more posteriorly (27). The rate of reduction of ${ }^{99 \mathrm{~m}} \mathrm{Tc}$ or ${ }^{99 \mathrm{~m}} \mathrm{Tc}-\mathrm{MIBI}$ uptake correlates with absolute volume reduction of the treated nodule (27), a finding thought to be related to necrosis following HIFU therapy. Isoechoic nodules showed greater reduction at 1 month than did hypoechoic nodules $(31.6 \% \pm 18.1 \%$ vs. $16.4 \% \pm 8.6 \%$, $\mathrm{P}=0.053)$. Nodules with markedly increased blood flow showed smaller volume reduction at 3 months than did less-vascularized nodules $(10.9 \% \pm 14.5 \%$ vs. $41.5 \% \pm 20.3 \%$, $\mathrm{P}=0.054)(29)$. A reduction in the concentration of antiTG antibody 4 days after treatment of anti-TG positive patients correlated with 6-month VRR (34). Moreover, the appearance of HEM during HIFU therapy was a significant predictor of nodule shrinkage at 6 months (35).

\section{Side effects after therapy}

The most common complication following HIFU treatment is vocal cord paresis (VCP), which has been reported in up to $1-2 \%$ of treated patients. This side effect may be prevented by keeping the focus of the beam at a safe distance, estimated to be $11 \mathrm{~mm}$, from the tracheoesophageal groove in which the laryngeal nerve is located (36). It is obligatory to examine vocal cord status just before and after treatment with HIFU. VCP or damage to other nerves (e.g., sympathetic trunk) is usually transitory in character, usually disappearing within 6 months after therapy.

Side effects related to the skin have also been observed, including allergy, paresthesia, irritation, and hyperpigmentation. Skin burns after HIFU therapy are very rare, occurring after $<1 \%$ of treatments, and can be prevented by the cooling system located on the VTU. Subcutaneous tissue edema, induration, and fibrosis are rare. Most skin and subcutaneous adverse effects are relieved just after treatment or within a few days.

\section{Future perspectives}

Future research on the use of HIFU to treat benign thyroid diseases can be split into two categories. The first is to optimize current treatment for thyroid nodules and the second is to search for other indications for HIFU treatment. Several animal studies show that nanodroplets potentiate the effects of the ultrasonic energy delivered during HIFU treatment. Use of nanodroplets (intravenous) increased ablation volumes, even at a much lower acoustic power, while significantly reducing the treatment time required to ablate a desired volume (37).

Because the propagation of ultrasound waves to target lesions causes significant pain, attempts are being made to reduce pain during treatment. Optimization of pain therapy without the need for general anesthesia seems to be crucial. Moreover, methods are being developed to treat patients effectively with HIFU without the need for anesthesia or analgesia. Patient comfort may also be improved by reducing treatment time, for example by the modified HIFU therapy procedure (BEAMOTION) provided by Theraclion. In this procedure the cooling phase is shortened, while maintaining treatment safety. The identification of early markers predicting the effects of treatment may enable patients who would not benefit from HIFU to start another treatment modality within a short 
period of time. To date, only the size of the treated nodule has been found to indicate the need for a second treatment session, with larger nodules being indicative of the need for further treatment. A reduction in anti-TG levels 4 days after HIFU therapy predicts nodule VRR, but only in patients that are positive for anti-TG antibodies.

\section{New treatment indications}

The effectiveness of HIFU ablation has been assessed in patients with medically refractory Graves disease (GD) (38), a condition usually treated with surgery or iodine therapy $\left({ }^{131} \mathrm{I}\right)$. In this study, 30 patients with GD underwent partial ablation of both thyroid lobes, with areas near the trachealesophageal groove and common carotid artery left unablated. After 12 months, eight patients (26.7\%) experienced relapse, one (3.3\%) experienced VCP, and two $(6.7 \%)$ experienced Horner syndrome, but none of these conditions was permanent. No changes in gland volume, antithyroid autoantibody levels, or ophthalmic parameters were observed after 12 months, suggesting that HIFU treatment may be safe and effective in patients with persistent or relapsed GD. One drawback to this treatment was that part of the thyroid tissue was not ablated, with this tissue being a potential source of recurrence. Advantages of this treatment is its avoidance of the potential complications of surgery and the radiation associated with ${ }^{131} \mathrm{I}$ treatment, as well as avoidance of increased autoantibodies to the thyrotropin receptor TRAB levels, or provoking or worsening pre-existing orbitopathy.

HIFU is a promising, new method of non-invasive therapy of benign thyroid nodules, but further prospective studies are needed to fully assess the effectiveness and safety of the method.

\section{Acknowledgments}

None.

\section{Footnote}

Conflicts of Interest: The authors have no conflicts of interest to declare.

Ethical Statement: The authors are accountable for all aspects of the work in ensuring that questions related to the accuracy or integrity of any part of the work are appropriately investigated and resolved.

\section{References}

1. Haugen BR, Alexander EK, Bible KC, et al. 2015 American Thyroid Association Management Guidelines for Adult Patients with Thyroid Nodules and Differentiated Thyroid Cancer: The American Thyroid Association Guidelines Task Force on Thyroid Nodules and Differentiated Thyroid Cancer. Thyroid 2016;26:1-133.

2. Durante C, Costante G, Lucisano G, et al. The natural history of benign thyroid nodules. JAMA 2015;313:926-35.

3. Puzziello A, Carrano M, Angrisani E, et al. Evolution of benign thyroid nodules under levothyroxine nonsuppressive therapy. J Endocrinol Invest 2014;37:1181-6.

4. Bergenfelz A, Jansson S, Kristoffersson A, et al. Complications to thyroid surgery: results as reported in a database from a multicenter audit comprising 3,660 patients. Langenbecks Arch Surg 2008;393:667-73.

5. Hahn SY, Shin JH, Na DG, et al. Ethanol Ablation of the Thyroid Nodules: 2018 Consensus Statement by the Korean Society of Thyroid Radiology. Korean J Radiol 2019;20:609-20.

6. Døssing H, Bennedbæk FN, Hegedüs L. Long-term outcome following laser therapy of benign cystic-solid thyroid nodules. Endocr Connect 2019. [Epub ahead of print].

7. Jeong WK, Baek JH, Rhim H, et al. Radiofrequency ablation of benign thyroid nodules: safety and imaging follow-up in 236 patients. Eur Radiol 2008;18:1244-50.

8. Heck K, Happel C, Grünwald F, et al. H. Percutaneous microwave ablation of thyroid nodules: effects on thyroid function and antibodies. Int J Hyperthermia 2015;31:560-7.

9. Korkusuz Y, Gröner D, Raczynski N, et al. Thermal ablation of thyroid nodules: are radiofrequency ablation, microwave ablation and high intensity focused ultrasound equally safe and effective methods? Eur Radiol 2018;28:929-35.

10. Wood RW, Loomis AL. The physical and biological effects of high-frequency sound-waves of great intensity. Lond Edinb Dublin Philos Mag J Sci 1927;4:417-36.

11. Fry WJ, Mosberg WH, Barnard JW, et al. Production of Focal Destructive Lesions in the Central Nervous System With Ultrasound. J Neurosurg 1954;11:471-8.

12. Wu F, Wang ZB, Zhu H, et al. Feasibility of US-guided high-intensity focused ultrasound treatment in patients with advanced pancreatic cancer: initial experience. Radiology 2005;236:1034-40. 
13. Rewcastle JC. High intensity focused ultrasound for prostate cancer: a review of the scientific foundation, technology and clinical outcomes. Technol Cancer Res Treat 2006;5:619-25.

14. Klingler C, Margreiter M, Marberger M. New ablative treatments for small renal masses: HIFU ablation. Arch Esp Urol 2013;66:79-89.

15. Illing RO, Kennedy JE, Wu F, et al. The safety and feasibility of extracorporeal high-intensity focused ultrasound (HIFU) for the treatment of liver and kidney tumours in a Western population. Br J Cancer 2005;93:890-5.

16. Peek MCL, Wu F. High-intensity focused ultrasound in the treatment of breast tumours. Ecancermedicalscience 2018;12:794.

17. Fruehauf JH, Back W, Eiermann A, et al. High-intensity focused ultrasound for the targeted destruction of uterine tissues: experiences from a pilot study using a mobile HIFU unit. Arch Gynecol Obstet 2008;277:143-50.

18. Shaw CJ, ter Haar GR, Rivens IH, et al. Pathophysiological mechanisms of high-intensity focused ultrasound-mediated vascular occlusion and relevance to non-invasive fetal surgery. J R Soc Interface 2014;11:20140029.

19. Esnault O, Franc B, Ménégaux F, et al. High-intensity focused ultrasound ablation of thyroid nodules: first human feasibility study. Thyroid 2011;21:965-73.

20. Schlesinger D, Benedict S, Diederich C, et al. MR-guided focused ultrasound surgery, present and future. Med Phys 2013;40:080901.

21. Haar GT, Coussios C. High intensity focused ultrasound: physical principles and devices. Int J Hyperthermia 2007;23:89-104.

22. Coussios CC, Farny CH, Haar GT, et al. Role of acoustic cavitation in the delivery and monitoring of cancer treatment by high-intensity focused ultrasound (HIFU). Int J Hyperthermia 2007;23:105-20.

23. Hariharan P, Myers MR, Robinson RA, et al. Characterization of high intensity focused ultrasound transducers using acoustic streaming. J Acoust Soc Am 2008;123:1706-19.

24. Kotewall N, Lang BHH. High-intensity focused ultrasound ablation as a treatment for benign thyroid diseases: the present and future. Ultrasonography 2019;38:135-42.

25. Lang BHH, Woo YC, Chiu KWH. Effect of perithyroidal lignocaine infusion (PLI) to pain experienced during highintensity focused ultrasound (HIFU) ablation of benign thyroid nodules. Eur Radiol 2019;29:5280-7.

26. Trimboli P, Bini F, Marinozzi F, et al. High-intensity focused ultrasound (HIFU) therapy for benign thyroid nodules without anesthesia or sedation. Endocrine 2018;61:210-5.

27. Korkusuz H, Fehre N, Sennert M, et al. Volume reduction of benign thyroid nodules 3 months after a single treatment with high-intensity focused ultrasound (HIFU). J Ther Ultrasound 2015;3:4.

28. Korkusuz H, Sennert M, Fehre N, et al. Localized Thyroid Tissue Ablation by High Intensity Focused Ultrasound: Volume Reduction, Effects on Thyroid Function and Immune Response. ROFO Fortschr Geb Rontgenstr Nuklearmed 2015;187:1011-5.

29. Kovatcheva RD, Vlahov JD, Stoinov JI, et al. Benign Solid Thyroid Nodules: US-guided High-Intensity Focused Ultrasound Ablation-Initial Clinical Outcomes. Radiology 2015;276:597-605.

30. Lang BHH, Woo YC, Wong CKH. High-Intensity Focused Ultrasound for Treatment of Symptomatic Benign Thyroid Nodules: A Prospective Study. Radiology 2017;284:897-906.

31. Lang BHH, Woo YC, Chiu KWH. Single-Session HighIntensity Focused Ultrasound Treatment in Large-Sized Benign Thyroid Nodules. Thyroid 2017;27:714-21.

32. Trimboli P, Pelloni F, Bini F, et al. L. High-intensity focused ultrasound (HIFU) for benign thyroid nodules: 2-year follow-up results. Endocrine 2019;65:312-7.

33. Lang BHH, Woo YC, Chiu KWH. Two-year efficacy of single-session high-intensity focused ultrasound (HIFU) ablation of benign thyroid nodules. Eur Radiol 2019;29:93-101.

34. Lang BHH, Woo YC, Chiu KWH. Changes in serum thyroglobulin and antithyroglobulin shortly following high-intensity focused ablation of benign thyroid nodules in patients with positive antithyroglobulin status. Int J Hyperthermia 2018;35:637-43.

35. Lang BHH, Woo YC, Chiu KWH. Significance of hyperechoic marks observed during high-intensity focused ultrasound (HIFU) ablation of benign thyroid nodules. Eur Radiol 2018;28:2675-81.

36. Lang BHH, Woo YC, Chiu KWH. Vocal cord paresis following single-session high intensity focused ablation (HIFU) treatment of benign thyroid nodules: incidence and risk factors. Int J Hyperthermia 2017;33:888-94.

37. Chang N, Lu S, Qin D, et al. Efficient and controllable thermal ablation induced by short-pulsed HIFU sequence 
assisted with perfluorohexane nanodroplets. Ultrason Sonochem 2018;45:57-64.

38. Lang BH, Woo YC, Wang IY, et al. Single-Session High-
Intensity Focused Ultrasound Treatment for Persistent or Relapsed Graves Disease: Preliminary Experience in a Prospective Study. Radiology 2017;285:1011-22.

Cite this article as: Pałyga I, Pałyga R, Młynarczyk J, Kopczyński J, Góźdź S, Kowalska A. The current state and future perspectives of high intensity focused ultrasound (HIFU) ablation for benign thyroid nodules. Gland Surg 2020;9(Suppl 2):S95-S104. doi: 10.21037/gs.2019.10.16 